\title{
Prostate cancer cell proliferation is suppressed by microRNA-3160-5p via targeting of F-box and WD repeat domain containing 8
}

\author{
PING LIN ${ }^{1 *}$, LIJUAN ZHU $^{1 *}$, WENJING SUN ${ }^{1}$, ZHENGKAI YANG $^{1}$, HUI SUN $^{1}$, \\ DONG LI $^{1}$, RONGJUN CUI ${ }^{1,2}$, XIULAN ZHENG ${ }^{1,3}$ and XIAOGUANG YU ${ }^{1}$ \\ ${ }^{1}$ Department of Biochemistry and Molecular Biology, Harbin Medical University, Harbin, Heilongjiang 150081; \\ ${ }^{2}$ Department of Biochemistry and Molecular Biology, Mudanjiang Medical University, Mudanjiang, \\ Heilongjiang 157011; ${ }^{3}$ Department of Ultrasonography and Medical Oncology, Harbin \\ Medical University Cancer Hospital, Harbin, Heilongjiang 150081, P.R. China
}

Received January 19, 2016; Accepted December 15, 2017

DOI: $10.3892 / \mathrm{ol} .2018 .8505$

\begin{abstract}
MicroRNAs (miRNAs/miRs), which are endogenous non-coding single-stranded RNAs 19-25 nucleotides in length, regulate gene expression by blocking translation or transcription repression. The present study revealed that miR-3160-5p was widely expressed in prostate cancer cells by reverse transcription-quantitative polymerase chain reaction. There was a negative association between the expression of miR-3160-5p and F-box and WD repeat domain containing 8 (Fbxw8) in prostate cancer DU145 cells. A luciferase activity assay was used to verify that Fbxw8 is the target of miR-3160-5p. In the present study, using MTT assay and cell cycle analysis, it was demonstrated that DU145 cell proliferation was repressed and the cell cycle was arrested in the $\mathrm{G}_{2} / \mathrm{M}$ cell cycle phase with upregulation of miR-3160-5p. Subsequent studies demonstrated that miR-3160-5p regulated the progression of the cell cycle in DU145 prostate cancer cells when the expression levels of phosphorylated cell division cycle (CDC)2, CDC25C and cyclin B1 were directly inhibited. Taken together, these findings revealed the mechanism underlying the role of miR-3160-5p in regulating the proliferation of DU145 cells and indicated that miR-3160-5p may serve as a promising novel therapeutic tool for prostate cancer.
\end{abstract}

Correspondence to: Professor Xiaoguang Yu, Department of Biochemistry and Molecular Biology, Harbin Medical University, 194 Xuefu Road, Harbin, Heilongjiang 150081, P.R. China

E-mail: xiaoguang_yu@hotmail.com

${ }^{*}$ Contributed equally

Key words: microRNA-3160-5p, cell proliferation, prostate cancer, F-box and WD repeat domain containing 8 , cell cycle

\section{Introduction}

Prostate cancer (PCa) is the most frequently diagnosed cancer in males. Furthermore, $\mathrm{PCa}$ is the second leading cause of cancer-associated mortality in males in the USA and there were 220,800 reported cases of PCa in the USA in 2015 (1). Additionally, the mortality and incidence rates of PCa have increased rapidly in China (2). Surgery and radiotherapy are successful treatments for early and localized tumors $(3,4)$, but the preferred therapy for advanced PCa is androgen-deprivation therapy. The majority of patients eventually develop androgen-independent or hormone-refractory $\mathrm{PCa}$ (5), and chemotherapy is the only remaining option for advanced hormone-refractory $\mathrm{PCa}$ (6). Further investigation into the molecular mechanisms underlying the tumorigenesis and development of $\mathrm{PCa}$, and the consequential development of novel targeted therapeutics, is required.

Numerous studies have demonstrated that microRNAs (miRNAs/miRs) negatively regulate the expression of a number of genes that are important for tumorigenesis and development, which highlights a novel mechanism underlying PCa pathogenesis (7-12). miRNAs are endogenously expressed small, non-coding, single-stranded RNAs. miRNAs are usually 21-23 nucleotides in length and they negatively regulate gene expression by binding to target gene 3 untranslated regions (3'-UTRs). This miRNA binding activity induces mRNA degradation or inhibition of translation (13-15). miRNA activity may therefore directly contribute to numerous fundamental biological and cellular processes, including stem cell differentiation, cell differentiation, and proliferation and apoptosis (16). Despite the increasing volume of evidence for the identification of miRNAs in PCa carcinogenesis, limited information is available regarding their specific roles and underlying mechanisms in PCa development.

Numerous F-box proteins are involved in tumorigenesis via their important roles in cell differentiation, cell cycle regulation and proliferation. As an F-box protein, only F-box and WD repeat domain containing 8 (Fbxw8) interact with S-phase kinase associated protein 1, ring-box 1 and cullin 7 
to form an E3 ligase $(17,18)$. Growth and cellular senescence is regulated by Fbxw8 targeting insulin receptor substrate 1 (IRS-1). IRS-1 is a critical mediator in insulin and insulin-like growth factor-1 signaling (19). Downregulation of Fbxw8 arrests cell cycle progression at the $\mathrm{G}_{2} / \mathrm{M}$ phase in JEG3 choriocarcinoma cells (20). miRNA-218, which targets Fbxw8, inhibits the proliferation of the human choriocarcinoma JEG-3 cell line (21).

The present study revealed that miR-3160-5p was highly expressed in PCa cells and that Fbxw8 is a target of miR-3160-5p. Overexpression of miR-3160-5p repressed DU145 cell proliferation and arrested the cell cycle in the $\mathrm{G}_{2} / \mathrm{M}$ phase by targeting Fbxw8. The results of the present study suggested that miR-3160-5p may serve as a novel potential therapeutic target for PCa.

\section{Materials and methods}

Cells and culture. Human PCa DU145, LNCaP and 22Rv1 cells were obtained from the American Type Culture Collection (Manassas, VA, USA) and were cultured in RPMI-1640 medium, supplemented with $10 \%$ fetal calf serum (FCS) (Gibco; Thermo Fisher Scientific, Inc., Waltham, MA, USA) $100 \mathrm{mg} / \mathrm{ml}$ streptomycin and $100 \mathrm{U} / \mathrm{ml}$ penicillin in $5 \% \mathrm{CO}_{2}$ at $37^{\circ} \mathrm{C}$.

RNA oligonucleotide and cell transfection. TargetScan (http://www.targetscan.org/vert_71/) was used to predict the microRNA which could bind to the 3'-UTR of the Fbxw8 transcript. Guangzhou RiboBio Co., Ltd. (Guangzhou, China) chemically synthesized miR-3160-5p mimics (cat no. miR10019212-1-5) and their scramble microRNA (miR-SCR) (cat no. miR01201-1-5). Cells were seeded onto 6 -well plates and, once the cell density had reached $60 \%$, $50 \mathrm{~nm}$ oligonucleotides were transfected into DU145 cells using Lipofectamine 2000 (Invitrogen; Thermo Fisher Scientific, Inc.), according to the manufacturer's protocol. The treated cells were harvested at 24 and $48 \mathrm{~h}$ for RNA or protein extraction, respectively.

Reverse transcription-quantitative polymerase chain reaction $(R T-q P C R)$. TRIzol $^{\circledR}$ reagent (Invitrogen; Thermo Fisher Scientific, Inc.) was used to extract total RNA from DU145 cells. For clearance of DNA contamination in the synthesis of RNA and cDNA, a PrimeScript ${ }^{\circledR}$ RT reagent kit with gDNA Eraser was used (Life Technologies; Thermo Fisher Scientific, Inc.). RT-qPCR was subsequently performed using the ABI-7500 system employing the SYBR ${ }^{\circledR}$ Select Master mix (Applied Biosystems; Thermo Fisher Scientific, Inc.). A total of $2 \mu \mathrm{g}$ RNA was used for reverse transcription. The mixture was incubated for $10 \mathrm{~min}$ at $25^{\circ} \mathrm{C}$, then $37^{\circ} \mathrm{C}$ for $120 \mathrm{~min}$, at last $5 \mathrm{~min}$ at $85^{\circ} \mathrm{C}$. The protocol of qPCR as follows: Denaturation at $95^{\circ} \mathrm{C}$ for $10 \mathrm{~min}$, then 40 amplification cycles of $95^{\circ} \mathrm{C}$ for $5 \mathrm{sec}$ and $60^{\circ} \mathrm{C}$ for $60 \mathrm{sec}$. miR-3160-5P, miR-548a-3p and miR-4426 expression levels in PCa LNCaP, 22Rv1 and DU145 cells, were assessed using RT-qPCR and were normalized to U6 small nuclear RNA. Fbxw8 mRNA expression levels in PCa cells were determined by qPCR and were normalized to $\beta$-actin. The relative expression was calculated using the $2^{-\Delta \Delta C q}$ method (22). The specific primers for the aforementioned
miRNAs, U6 and Fbxw8, were synthesized by Guangzhou RiboBio Co., Ltd. The sequences of primers were as follows: Fbxw8, forward: 5'-TCAGGGGATGTGAGAGTGTGG-3', reverse: 5'-TCAGGGGATGTGAGAGTGTGG-3', $\beta$-actin, forward: 5'-CATGTACGTTGCTATCCAGGC-3', reverse: 5'-CTCCTTAATGTCACGCACGAT-3'.

Western blot analysis. Radioimmunoprecipitation assay buffer (Beyotime Institute of Biotechnology, P.R. China) was used to extract total cellular proteins of DU145, PC-3 and 22RV1 cells, then the protein concentration was detected using a bicinchoninic acid assay according to the manufacturer's protocol (Pierce ${ }^{\mathrm{TM}}$ BCA Protein Assay Kit; cat no. 23227; Life Technologies; Thermo Fisher Scientific, Inc.). A total of $50 \mu \mathrm{g}$ proteins/well were separated using a denatured $10 \%$ polyacrylamide gel and were subsequently transferred to a nitrocellulose membrane. The membranes were blocked with 5\% non-fat milk for $1 \mathrm{~h}$ at room temperature, then incubated with primary antibodies at $4^{\circ} \mathrm{C}$ overnight. Antibodies against Fbxw8 (ab85647; 1:500) were obtained from Abcam (Cambridge, UK). Antibodies against $\beta$-actin (60008-1-Ig; 1:1,000) were obtained from ProteinTech Group, Inc. (Chicago, IL, USA). p-CDC2 (BM3428; 1:200), CDC-2 (BM0027; 1:200) and CDC-25C (BM1580; 1:200) were purchased from Boster Biological Technology Co., Ltd. (Wuhan, China). Subsequently, the membranes were rinsed three times with Tris-buffered saline with Tween-20 for $10 \mathrm{~min}$ at room temperature and incubated with horseradish peroxidase-conjugated secondary antibodies (A16104; 1:2,000) for $1 \mathrm{~h}$. Enhanced chemiluminesence was performed using Western blot detection reagents according to the manufacturer's protocol (Pierce ${ }^{\mathrm{TM}}$ ECL Plus Western Blotting Substrate; cat no. 32132; Life Technologies; Thermo Fisher Scientific, Inc.) in order to visualize the signals.

MTT assay. Cells were seeded at $3 \times 10^{3}$ onto 96-well plates and were stained once per day for 5 consecutive days with $100 \mu \mathrm{l}$ sterile MTT dye $(0.5 \mathrm{mg} / \mathrm{ml}$; Sigma-Aldrich; Merck KGaA, Darmstadt, Germany) at $37^{\circ} \mathrm{C}$ for $4 \mathrm{~h}$. This was followed by the removal of the culture medium and the addition of $150 \mu \mathrm{l}$ of DMSO (Sigma-Aldrich; Merck KGaA) to dissolve the purple formazan. The absorbance was detected at $570 \mathrm{~nm}$ using $655 \mathrm{~nm}$ as the reference wavelength in order to account for background interference. The experiments were performed in triplicate.

Luciferase reporter assay. In a 12-well plate, PCa DU145 cells were seeded at $1.5 \times 10^{5}$ cells/well. A psiChECK-2 Fbxw8 3'-UTR WT vector (500 ng) or miR-3160-5P site mutation vector $(500 \mathrm{ng})$ were co-transfected with miRNA-3160-5P mimic using Lipofectamine 2000. After 48 h, luciferase activities were detected using a Dual Luciferase Reporter Assay kit (Promega Corporation, Madison, WI, USA). The results are expressed as ratio of Firefly luciferase to Renilla luciferase. Each experiment was performed three times and the results are presented as the mean \pm standard deviation.

Cell cycle assay. DU145 cells were transfected with miR-3160-5P for 48 h, then harvested. Cold phosphate-buffered saline (PBS) was used to wash the cells following harvesting, 
A

Fbxw8-3'UTR(4206-4212) 5' ...GAAACCAGAGUGCCCAGAAAGCU...

has-miR-3160-5P

Fbxw8-3'UTR(52-59) 5' ...AAGAACCAGUUUUAUCCAUCUUA...

has-miR-4426

$3^{\prime} \ldots$

| |

| | | | ||

Fbxw8-3'UTR(43-50) 5' ...AAAAAUGGGAAGAACCAGUUUUA...

has-miR-548a-3p
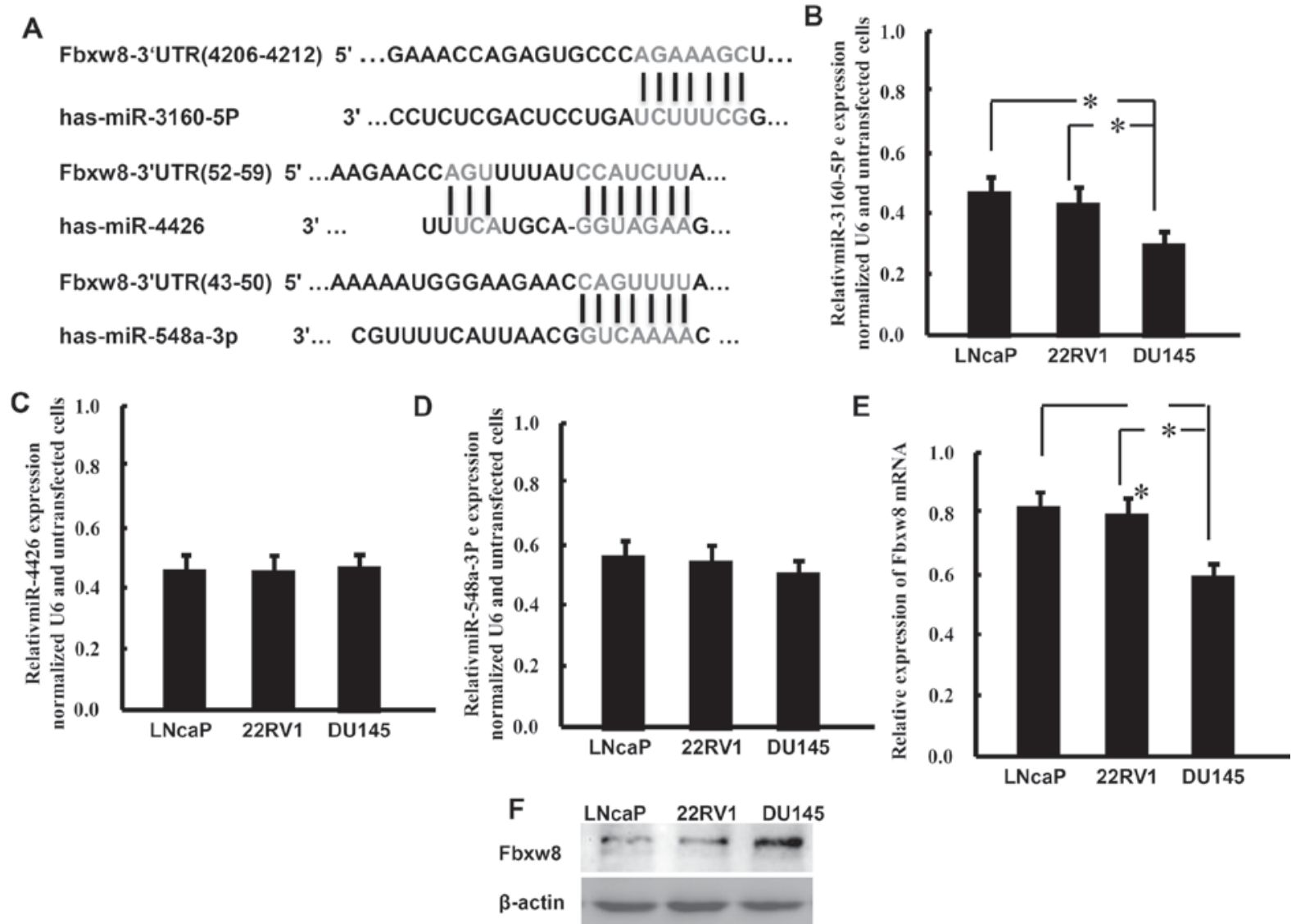

Figure 1. miR-3160-5P expression and Fbxw8 protein expression levels were inversely associated in PCa cell lines. (A) Predicted miRNA targeted sequences in the 3'-UTR of Fbxw8. miRNA expression levels in PCa cell lines were assessed by reverse transcription-quantitative polymerase chain reaction and were normalized to U6. The results demonstrated that (B) miR-3160-5P, (C) miR-4426 and (D) miR-548a-3p were expressed in PCa LNCaP, $22 \mathrm{Rv1}$ and DU145 cells; Fbxw8 (E) mRNA and (F) protein expression in PCa LNCaP, 22Rv1 and DU145 cells were also determined. Band intensities for Fbxw8 were normalized to $\beta$-actin. " $\mathrm{P}<0.05$, representative data from three experiments with similar results are presented as the mean \pm standard deviation. miR, microRNA; Fbxw8, F-box and WD repeat domain containing 8; PCa, prostate cancer; 3'-UTR, 3' untranslated region.

then cells were fixed in $70 \%$ ethanol overnight at $4^{\circ} \mathrm{C}$. The cells were washed again in cold PBS three times and incubated with $0.5 \mu \mathrm{g} / \mathrm{ml}$ RNase A (Sigma-Aldrich; Merck KGaA) for $30 \mathrm{~min}$ at $37^{\circ} \mathrm{C}$. Subsequently, the cells were stained with $50 \mathrm{mg} / \mathrm{ml}$ propidium iodide (Sigma-Aldrich; Merck KGaA) at room temperature for $20 \mathrm{~min}$. Fluorescence-activated cell sorter (FACS) analysis was performed using a flow cytometer (BD Biosciences, San Jose, CA, USA). ModFit LT software (version 3.2.1; BD Biosciences) was used for analysis.

Statistical analysis. The results are expressed as the mean \pm SD. One-way analysis of variance was performed using SPSS version 17.0 (SPSS, Inc., Chicago, IL, USA). Multiple comparison between the groups was performed using Fisher's least significant difference test. $\mathrm{P}<0.05$ was considered to indicate a statistically significant difference.

\section{Results}

miR-3160-5P is expressed in PCa cells. Targetscan predicted that miR-3160-5P, miR-548a-3p and miR-4426 may target the 3'-UTR of the Fbxw8 transcript (Fig. 1A). The present study detected the expression patterns of these miRNAs in the PCa LNCaP, 22Rv1 and DU145 cell lines using RT-qPCR analysis (Fig. 1B-D). The results demonstrated that these miRNAs were expressed in PCa cells. Compared with the other two cell lines and miRNAs, DU145 cells exhibit significantly lower expression levels of miR-3160-5P. Conversely, DU145 cells expressed markedly higher mRNA and protein levels of Fbxw8 compared with LNCaP and 22Rv1 cells (Fig. 1E and F). These results demonstrated that lower miR-3160-5P expression levels were associated with higher expression levels of Fbxw8 protein in DU145 cells.

$m i R-3160-5 P$ targets Fbxw8 $m R N A$. It was predicted that miR-3160-5p negatively regulated the expression of Fbxw8. There is a negative association between the expression of miR-3160-5p and Fbxw8 in DU145, therefore DU145 cells were selected for the present study. DU145 cells were transfected with miR-3160-5P in order to investigate the association between miR-3160-5P and Fbxw8 in DU145 cells. RT-qPCR revealed that the expression of miR-3160-5P was significantly upregulated $48 \mathrm{~h}$ after transfection compared with expression in the control group (Fig. 2A). In addition, RT-qPCR and western blot analysis demonstrated that enhanced miR-3160-5P expression in DU145 cells significantly repressed Fbxw8 mRNA and protein expression (Fig. 2B and C). The 
A

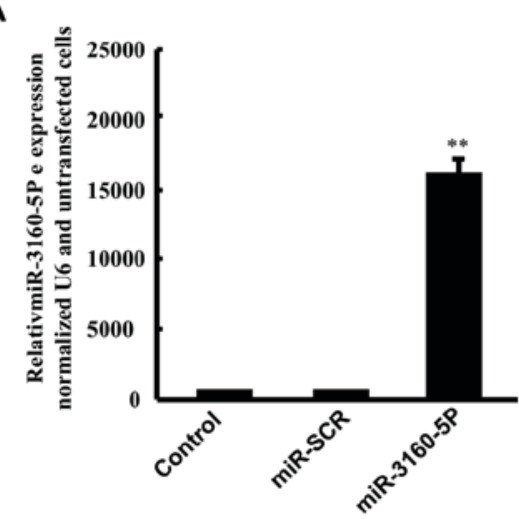

D
B

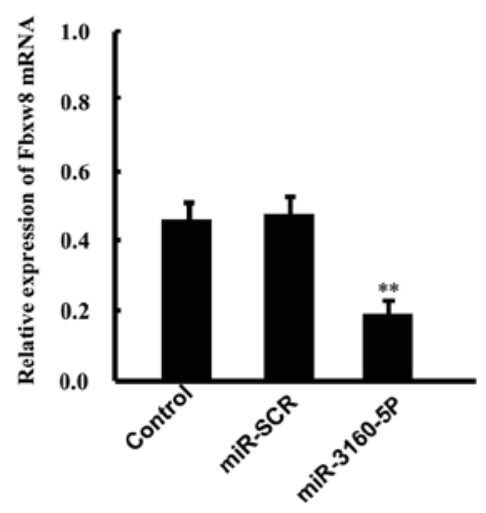

C

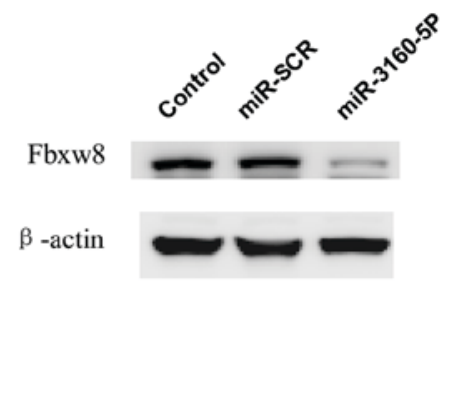

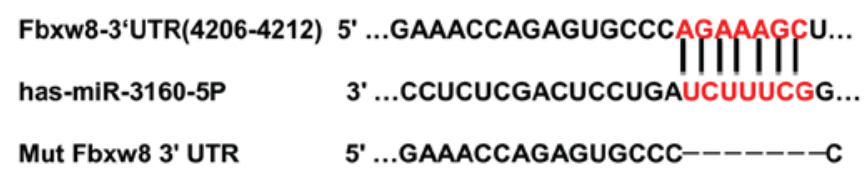

E

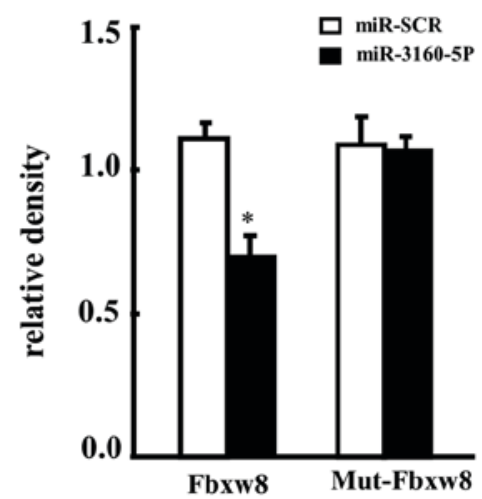

Figure 2. Fbxw8 is targeted by miR-3160-5P following binding to the 3'-UTR. (A) RT-qPCR was used to assess the upregulated expression of miR-3160-5P in DU145 cells transfected with miR-3160-5P mimics, compared with controls or miR-SCR-transfected cells. Fbxw8 (B) mRNA and (C) protein expression levels in DU145 cells that were transfected with miR-3160-5P or miR-SCR were assessed by RT-qPCR and western blot analysis. (D) The predicted miR-3160-5P binding site in the Fbxw8 3'-UTR and its mutated version due to site mutagenesis. (E) The relative luciferase activities of the WT and Mut Fbxw8 3'-UTR regions (mean $\pm \mathrm{SD}$ of three independent experiments, performed in triplicate). ${ }^{* *} \mathrm{P}<0.01$. The mean $\pm \mathrm{SD}$ of three representative experiments are presented. RT-qPCR, reverse transcription-quantitative polymerase chain reaction; miR, microRNA; miR-SCR, scramble microRNA; Fbxw8, F-box and WD repeat domain containing 8; 3'-UTR, 3' untranslated region; WT, wild type; Mut, mutant; SD, standard deviation.

present study also constructed a reporter vector consisting of the luciferase coding sequence followed by the 3'-UTR of Fbxw8 (WT-Fbxw8) in order to determine whether the 3'-UTR of Fbxw8 mRNA is a functional target of miR0316-5P in DU145 cells, as well as a mutant-Fbxw8 3'-UTR luciferase reporter vector (Mut-Fbxw8) by deleting the predicted 7-base pair miR-3160-5P binding site in the 3'-UTR of the Fbxw8 transcript (Fig. 2D). The WT-Fbxw8 or Mut-Fbxw8 vector and miR-3160-5P mimics or control RNA were co-transfected into DU145 cells, respectively. miR-3160-5P-transfected cell luciferase activity was significantly reduced compared with that in the control cells (Fig. 2E). In addition, the mutant putative binding site abolished miR-3160-5P-mediated repression of luciferase activity.

miR-3160-5P inhibits cell growth in PCa DU145 cells. We previously reported that Fbxw8 has important effects on cell proliferation as a potential oncogene in human cancer (13). Therefore, the present study hypothesized that miR-3160-5P may repress DU145 cell proliferation via Fbxw8 downregulation. To elucidate the functional significance of miR-3160-5P in DU145 cells, the present study examined its effect on proliferation using MTT and cell cycle analysis. It was revealed that miR-3160-5P significantly decreased the proliferation of DU145 cells (Fig. 3A). Furthermore, FACS revealed that the percentage of cells in the $\mathrm{G}_{2} / \mathrm{M}$ phase was increased following miR-3160-5P transfection (Fig. 3B and C). These results demonstrated that miR-3160-5P inhibited DU145 cell proliferation.

Induced expression of miR-3160-5P inhibited p-CDC2, $C D C 25 C$, and cyclin $B 1$ expression. Subsequently, the present study evaluated the expression levels of proteins that were responsible for the $\mathrm{G}_{2} / \mathrm{M}$ cell cycle phase transition by western blot analysis, since downregulation of Fbxw8 induced $\mathrm{G}_{2} / \mathrm{M}$ arrest in DU145 cells. These results were consistent with the cell cycle assay results. miR-3160-5P was decreased in p-CDC2, CDC25C and cyclin B1 in DU145 cells following a 48-h treatment (Fig. 4A and B). Treatment with miR-3160-5P did not affect the expression level of total CDC2.

\section{Discussion}

The second leading cause of cancer-associated mortality in males is PCa. The mechanisms underlying PCa development and progression remain unknown despite the fact that certain mechanisms that serve a significant role in PCa pathogenesis have been elucidated.

The inability of a cell to modulate its proliferation is a distinctive feature of cancer. The present study identified a 
A

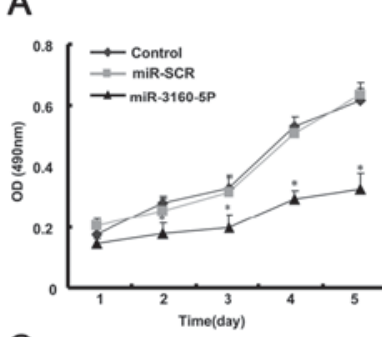

\section{B}

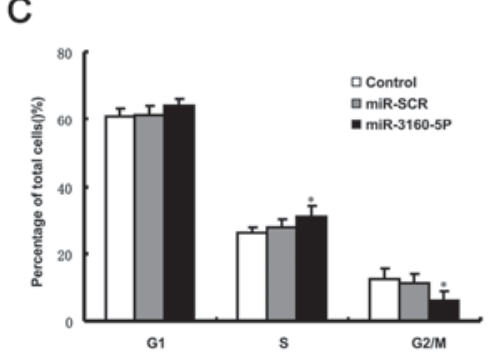

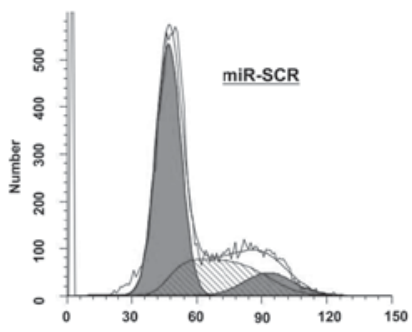

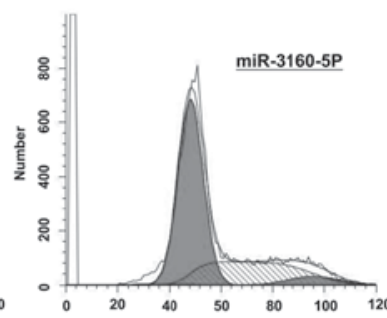

Figure 3. miR-3160-5P inhibited the proliferation of DU145 cells. (A) Proliferation of DU145 cells transfected with miR-3160-5P mimics or miR-SCR were detected by an MTT assay. (B) FACS analysis of the cell cycle. (C) Cell cycle distribution percentage. "P<0.05, compared with miR-SCR. Representative results of three experiments are presented as the mean \pm standard deviation. miR, microRNA; miR-SCR, scramble microRNA; OD, optical density.

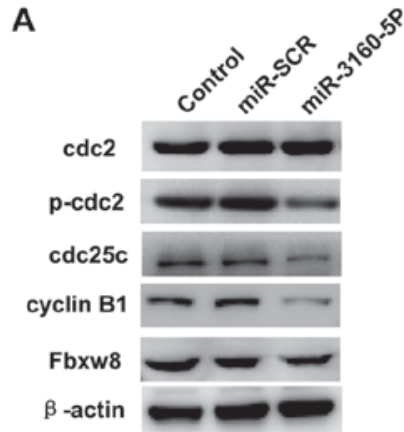

B

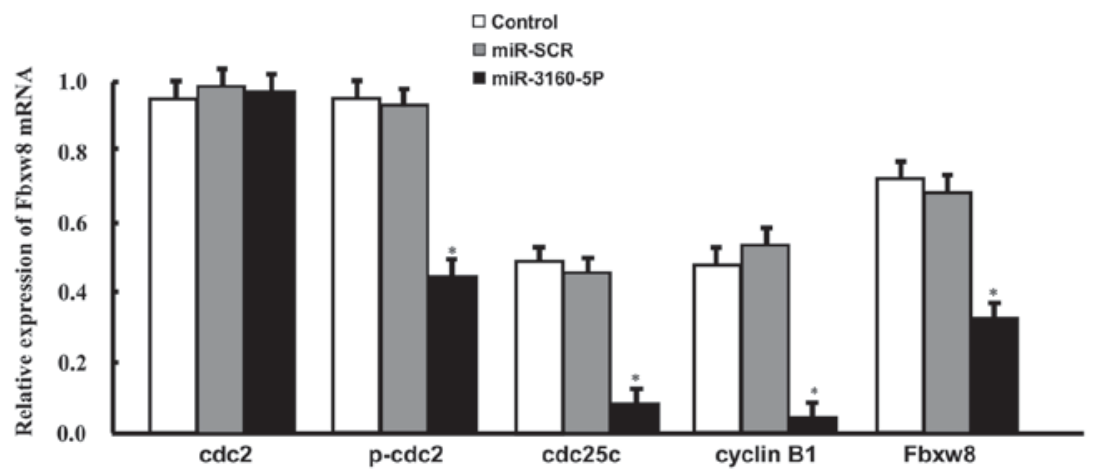

Figure 4. Effects of miR-3160-5P on cell cycle regulator expression in DU145 cells. (A) The expression of cell cycle regulators was analyzed by western blot analysis. (B) The intensities of the bands relevant to $\mathrm{p}-\mathrm{CDC} 2$, total CDC-2, CDC25C, cyclin B1 and Fbxw8 protein were normalized to that of $\beta$-actin. Representative results of three experiments are presented as the mean \pm standard deviation. "P $<0.05$ vs. miR-SCR. miR, microRNA; CDC, cell division cycle; Fbxw8, F-box and WD repeat domain containing 8; miR-SCR, scramble microRNA.

novel miRNA that regulates Fbxw8 expression and elucidated the role of this novel miRNA on the proliferation of $\mathrm{PCa}$ DU145 cells. Using Targetscan, it was initially hypothesized that miR-3160-5P may bind to the 3'-UTR of the Fbxw8 transcript. The present study evaluated luciferase activity using a vector containing the two alleles to demonstrate that miR-3160-5P directly targets the 3'-UTR. There was significantly decreased activity with the luciferase vector that exhibited the mutant-type allele compared with the wild-type vector. Overexpression of miR-3160-5P reduced the luciferase activity, indicating that miR-3160-5P directly inhibited Fbxw8 expression. Fbxw 8 mRNA and protein expression levels were decreased following transfection with miR-3160-5P mimics, which occurred in a precursor miRNA concentration-dependent manner. It has been suggested that miR-3160-5P suppressed endogenous Fbxw8 protein expression by regulating the stability of Fbxw 8 mRNA transcripts. Considering the results of the present study, it was suggested that miR-3160-5P negatively regulates Fbxw8.
miRNAs serve an important role in the progression of the majority of types of human cancer. They participate in numerous cellular processes, including proliferation, differentiation, apoptosis, metastasis, stem cell maintenance and metabolism (13,23-27). miRNAs are involved in PCa pathogenesis via the regulation of oncogene upregulation or tumor suppressor downregulation in PCa (13). The results from RT-qPCR in the present study demonstrated that miR-3160-5P, which is a potential miRNA that targets the Fbxw8 3'-UTR, was downregulated in DU145 cells. The results of the present study revealed that miR-3160-5P participated in the proliferation of DU145 cells. The present study indicated that miRNA may act as a potential tumor suppressor in solid cancer.

An increasing volume of data has revealed the role of Fbxw8 E3 ligase in cancer $(20,21,28,29)$. Impaired proliferation kinetics was identified in the Fbxw $8^{-/-}$mouse embryonic fibroblasts (30). The degradation of cyclin D1 by Fbxw8 in HCT116 cells was revealed to be required for cancer cell proliferation (28). Endogenous homeodomain-interacting protein kinase 1 expression was 
restored by downregulation of Fbxw8 and it also suppresses cell proliferation in pancreatic ductal adenocarcinoma (29).

The present study investigated the hypothesis that miR-3160-5P-mediated inhibition of Fbxw8 regulated the proliferation of DU145 cells. Notably, miR-3160-5P and Fbxw8 protein expression levels were negatively associated with each other in DU145 cells lines.

Upregulated miR-3160-5P expression suppressed the proliferation of DU145 cells and increased the number of cells arrested in the $\mathrm{G}_{2} / \mathrm{M}$ phase of the cell cycle. The present study confirmed that miR-3160-5P and Fbxw8 are associated with each other. It was also revealed that miR-3160-5P inhibited DU145 cell proliferation by targeting Fbxw8. Target-inhibition of Fbxw8 arrested cell cycle progression at the $\mathrm{G}_{2} / \mathrm{M}$ phase in choriocarcinoma JEG3 cells by decreasing the expression level of $\mathrm{G}_{2} / \mathrm{M}$-associated cell cycle regulators and increasing the expression level of p27 (20,21). The in-depth molecular mechanisms underlying cell cycle arrest induced by miR-3160-5P were investigated further. A number of cyclin-dependent kinases (CDKs) were involved in the regulation of the cell cycle $(31,32)$. Activation of CDK1 and $\mathrm{CDK} 2$ is primarily associated with cyclin $\mathrm{A}$ and $\mathrm{B} 1$ in the progression of the $\mathrm{G}_{2} / \mathrm{M}$ cell cycle phase. Cyclin B1 and CDC2 kinase serve important roles in the initiation stage of the $M$ phase (33). Previous studies demonstrated that the activation of CDC2 kinase depends on the accumulation of cyclin B and dephosphorylation of CDC2 (34). The present study confirmed that there is a vital molecular association between Fbxw8, miR-3160-5P, cdc2 kinase, cyclin $\mathrm{B} 1$ and cdc25c protein expression. At the protein level, induced expression of miR-3160-5P in DU145 cells was revealed to effectively inhibit Fbxw8, cyclin B1, CDC2 kinase and total CDC25C expression. This suggested a potential inverse association between miR-3160-5P and Fbxw8 in DU145 cells. The main effect of Fbxw8 is an autocrine effect as miR-3160-5P downregulates Fbxw8 mRNA and protein levels in the cells. In addition, the present study suggested that miR-3160-5P inhibited cyclin $\mathrm{B} 1, \mathrm{CDC} 2$ kinase and $\mathrm{CDC} 25 \mathrm{C}$ expression levels via Fbxw8 signaling. The results of the present study sufficiently demonstrated that miR-3160-5P, at least in part, serves a role in the suppression of cellular proliferation due to the direct inhibition of Fbxw8 expression.

In conclusion, to the best of our knowledge, the present study was the first to demonstrate that miR-3160-5P is a tumor suppressor in PCa. miR-3160-5P inhibited cell proliferation by directly inhibiting the expression of Fbxw8 and indirectly suppressing the expression of cyclin B1, CDC2 kinase and CDC25C. miR-3160-5P is a potential therapeutic target for PCa. miR-3160-5P effects on PCa proliferation in vivo, as well as the underlying mechanisms, remain unknown. Future studies are required to elucidate the effect of anti-miR-3160-5P therapy in the clinic.

\section{Acknowledgements}

Not applicable.

\section{Funding}

The present study was supported by the National Natural Science Foundation of China (grant no. 81172417) to Xiaoguang Yu.

\section{Availability of data and materials}

The datasets used and/or analyzed during the current study are available from the corresponding author on reasonable request.

\section{Authors' contributions}

PL, LZ and XY conception and design, provision of study material, data analysis and interpretation, collection and assembly of data. PL, LZ, WS, ZY, HS, DL, RC, XZ: experiment performing. PL and XY: manuscript writing.

\section{Ethics approval and consent to participate}

Not applicable.

\section{Consent for publication}

Not applicable.

\section{Competing interests}

The authors declare that they have no competing interests.

\section{References}

1. Siegel RL, Miller KD and Jemal A: Cancer statistics, 2015. CA Cancer J Clin 65: 25-29, 2015.

2. Chen W, Zheng R, Baade PD, Zhang S, Zeng H, Bray F, Jemal A, $\mathrm{Yu}$ XQ and He J: Cancer statistics in China, 2015. CA Cancer J Clin 66: 115-132, 2016.

3. Moore TH, King AJ, Evans M, Sharp D, Persad R and Huntley AL: Supportive care for men with prostate cancer: Why are the trials not working? A systematic review and recommendations for future trials. Cancer Med 4: 1240-1251, 2015.

4. Hudson SV, O'Malley DM and Miller SM: Achieving optimal delivery of follow-up care for prostate cancer survivors: Improving patient outcomes. Patient Relat Outcome Meas 6: 75-90, 2015.

5. Miyamoto H, Messing EM and Chang C: Androgen deprivation therapy for prostate cancer: Current status and future prospects. Prostate 61: 332-353, 2004.

6. Helsen C, Van den Broeck T, Voet A, Prekovic S, Van Poppel H, Joniau S and Claessens F: Androgen receptor antagonists for prostate cancer therapy. Endocr Relat Cancer 21: T105-T118, 2014.

7. Xu B, Huang Y, Niu X, Tao T, Jiang L, Tong N, Chen S, Liu N, Zhu W and Chen M: Hsa-miR-146a-5p modulates androgen-independent prostate cancer cells apoptosis by targeting ROCK1. Prostate 75: 1896-1903, 2015.

8. Khanmi K, Ignacimuthu S and Paulraj MG: MicroRNA in prostate cancer. Clin Chim Acta 451: 154-160, 2015.

9. Fang YX and Gao WQ: Roles of microRNAs during prostatic tumorigenesis and tumor progression. Oncogene 33: 135-147, 2014.

10. Hassan O, Ahmad A, Sethi S and Sarkar FH: Recent updates on the role of microRNAs in prostate cancer. J Hematol Oncol 5: 9, 2012.

11. Hsu TI, Hsu CH, Lee KH, Lin JT, Chen CS, Chang KC, Su CY, Hsiao M and Lu PJ: MicroRNA-18a is elevated in prostate cancer and promotes tumorigenesis through suppressing STK4 in vitro and in vivo. Oncogenesis 3: e99, 2014.

12. Shi XB, Xue L, Yang J, Ma AH, Zhao J, Xu M, Tepper CG, Evans CP, Kung HJ and deVere White RW: An androgen-regulated miRNA suppresses Bak1 expression and induces androgen-independent growth of prostate cancer cells. Proc Natl Acad Sci USA 104: 19983-19988, 2007.

13. Wang L, Li B, Li L and Wang T: MicroRNA-497 suppresses proliferation and induces apoptosis in prostate cancer cells. Asian Pac J Cancer Prev 14: 3499-3502, 2013. 
14. Nazarov PV, Reinsbach SE, Muller A, Nicot N, Philippidou D, Vallar L and Kreis S: Interplay of microRNAs, transcription factors and target genes: Linking dynamic expression changes to function. Nucleic Acids Res 41: 2817-2831, 2013.

15. Cellini F, Morganti AG, Genovesi D, Silvestris N and Valentini V: Role of microRNA in response to ionizing radiations: Evidences and potential impact on clinical practice for radiotherapy. Molecules 19: 5379-5401, 2014.

16. Bartel DP: MicroRNAs: Target recognition and regulatory functions. Cell 136: 215-233, 2009.

17. Dias DC, Dolios G, Wang R and Pan ZQ: CUL7: A DOC domain-containing cullin selectively binds Skp1.Fbx29 to form an SCF-like complex. Proc Natl Acad Sci USA 99: 16601-16606, 2002.

18. Huber C, Dias-Santagata D, Glaser A, O'Sullivan J, Brauner R, Wu K, Xu X, Pearce K, Wang R, Uzielli ML, et al: Identification of mutations in CUL7 in 3-M syndrome. Nat Genet 37: 1119-1124, 2005.

19. Xu X, Sarikas A, Dias-Santagata DC, Dolios G, Lafontant PJ, Tsai SC, Zhu W, Nakajima H, Nakajima HO, Field LJ, et al: The CUL7 E3 ubiquitin ligase targets insulin receptor substrate 1 for ubiquitin-dependent degradation. Mol Cell 30: 403-414, 2008.

20. Lin P, Fu J, Zhao B, Lin F, Zou H, Liu L, Zhu C, Wang H and Yu X: Fbxw8 is involved in the proliferation of human choriocarcinoma JEG-3 cells. Mol Biol Rep 38: 1741-1747, 2011.

21. Shi D, Tan Z, Lu R, Yang W and Zhang Y: MicroRNA-218 inhibits the proliferation of human choriocarcinoma JEG-3 cell line by targeting Fbxw8. Biochem Biophys Res Commun 450: 1241-1246, 2014

22. Livak KJ and Schmittgen TD: Analysis of relative gene expression data using real-time quantitative PCR and the 2(-Delta Delta C(T)) method. Methods 25: 402-408, 2001

23. Bartel DP: MicroRNAs: Genomics, biogenesis, mechanism, and function. Cell 116: 281-297, 2004.

24. Hsieh IS, Chang KC, Tsai YT, Ke JY, Lu PJ, Lee KH, Yeh SD, Hong TM and Chen YL: MicroRNA-320 suppresses the stem cell-like characteristics of prostate cancer cells by downregulating the Wnt/beta-catenin signaling pathway. Carcinogenesis 34: 530-538, 2013
25. Liu C, Kelnar K, Vlassov AV, Brown D, Wang J and Tang DG: Distinct microRNA expression profiles in prostate cancer stem/progenitor cells and tumor-suppressive functions of let-7. Cancer Res 72: 3393-3404, 2012.

26. Jin M, Zhang T, Liu C, Badeaux MA, Liu B, Liu R, Jeter C, Chen X, Vlassov AV and Tang DG: miRNA-128 suppresses prostate cancer by inhibiting BMI-1 to inhibit tumor-initiating cells. Cancer Res 74: 4183-4195, 2014.

27. Kurisetty VV, Lakshmanaswamy $\mathrm{R}$ and Damodaran C: Pathogenic and therapeutic role of miRNAs in breast cancer. Front Biosci (Landmark Ed) 19: 1-11, 2014

28. Okabe H, Lee SH, Phuchareon J, Albertson DG, McCormick F and Tetsu O: A critical role for FBXW8 and MAPK in cyclin D1 degradation and cancer cell proliferation. PLoS One 1: e128, 2006.

29. Wang H, Chen Y, Lin P, Li L, Zhou G, Liu G, Logsdon C, Jin J, Abbruzzese JL, Tan TH and Wang H: The CUL7/F-box and WD repeat domain containing 8 (CUL7/Fbxw8) ubiquitin ligase promotes degradation of hematopoietic progenitor kinase 1. J Biol Chem 289: 4009-4017, 2014.

30. Tsunematsu R, Nishiyama M, Kotoshiba S, Saiga T, Kamura T and Nakayama KI: Fbxw8 is essential for Cul1-Cul7 complex formation and for placental development. Mol Cell Biol 26: 6157-6169, 2006

31. Molinari M: Cell cycle checkpoints and their inactivation in human cancer. Cell Prolif 33: 261-274, 2000.

32. Hartwell LH and Weinert TA: Checkpoints: Controls that ensure the order of cell cycle events. Science 246: 629-634, 1989.

33. Chiang NJ, Lin CI, Liou JP, Kuo CC, Chang CY, Chen LT and Chang JY: A novel synthetic microtubule inhibitor, MPT0B214 exhibits antitumor activity in human tumor cells through mitochondria-dependent intrinsic pathway. PLoS One 8: e58953, 2013.

34. King KL and Cidlowski JA: Cell cycle and apoptosis: Common pathways to life and death. J Cell Biochem 58: 175-180, 1995. 